\title{
Betonarme kirişlerde ultra yüksek dayanımlı beton kullanımının eğilme performansına etkisi
}

\author{
Tamer BİROL ${ }^{*}$, Altuğ YAVAŞ \\ Balıkesir Üniversitesi Mühendislik Fakültesi İnşaat Mühendisliği Bölümü, Çağış kampüsü, Balıkesir. \\ Geliș Tarihi (Recived Date): 28.09.2017 \\ Kabul Tarihi (Accepted Date): 10.11.2017
}

\section{Özet}

Bu çalışmada, Ultra Yüksek Dayanımlı Beton’un (UYDB) betonarme kirişlerin eğilme davranışına etkileri deneysel ve sayısal olarak incelenmiştir. Deneysel kısımda ortalama $135 \mathrm{MPa}$ ' lı UYDB kullanılarak düşük ve yüksek donatı oranlarına sahip dört adet betonarme kiriş üretilmiş ve dört noktalı eğilme altında test edilmiştir. Sayısal kısımda ise test kirişleri için UYDB ve normal dayanımlı beton kullanılarak kesit analizleri gerçekleştirilmiş ve sonuçlar karşılaştırılmıştır. Sonuç olarak UYDB'nin özellikle yüksek donatı oranlart için ĕgilme sünekliği, moment kapasitesi ve ĕgilme rijitliği parametreleri bakımından normal dayanıml betona göre önemli avantajlar sağladığı görülmüştür. UYDB ile üretilen kirişlerin TS 500'de verilen maksimum donatı sınırının aşılmasına rağmen yeterli sünekliği sağladığı, hatta daha yüksek donatı oranlarının da kullanılabileceği düşünülmektedir.

Anahtar kelimeler: Ultra yüksek dayanım, normal dayanım, beton, ě̆ilme, donatı oranı, betonarme kiriş.

\section{Impact of ultra high strength concrete to flexural performance of $\mathrm{RC}$ beams}

\begin{abstract}
In this study, the effects of Ultra High Strength Concrete (UHSC) on the flexural behavior of reinforced concrete beams have been investigated experimentally and numerically. In the experimental section, four reinforced concrete beams with low and high reinforcement ratios were produced by using UHSC with an average compressive strength of $135 \mathrm{MPa}$ and tested under four-point loading. In the numerical section,
\end{abstract}

\footnotetext{
*Tamer BİROL, tbirol@balikesir.edu.tr, http://orcid.org/0000-0003-2428-6202

Altuğ YAVAŞ, ayavas@balikesir.edu.tr, http://orcid.org/0000-0002-2619-8671
} 
cross section analyzes were carried out by using UHSC and normal strength concrete for test beams and the results were compared. It has been observed that UHSC provides significant advantages over normal strength concrete in terms of flexural ductility, moment capacity and flexural stiffness especially for high reinforcement ratios. It is considered that the beams produced with UHSC provide sufficient ductility even though the limit given in TS 500 is exceeded and higher reinforcement ratios can be used.

Keywords: Ultra high strength, normal strength, concrete, flexure, reinforcement ratio, reinforced concrete beam.

\section{Giriş}

Günümüzde yüksek binalara ve büyük açıklıklı yapı türlerine olan gereksinimlerin artması, beraberinde çok yüksek dayanımlı betonlara olan talebi de arttırmaktadır. Bu tür betonların basınç dayanımları yanında elastisite modüllerinin de geleneksel betonlara göre yüksek olması, yapılarda daha küçük kesitli (narin) eleman kullanımına olanak vermektedir [1]. Buna bağlı olarak yapı ağırlığı, deprem yükleri ve temel boyutları azaltılarak önemli ekonomi sağlanmakta ve daha estetik yapılar elde edilebilmektedir [2]. Ayrıca, bu tür betonlar çok sıkı içyapıları sayesinde geleneksel betonlara göre üstün durabiliteye sahip olmakta ve bunun sonucunda yapıların uzun ömürlü olmasını sağlamaktadır [3, 4].

Son yıllarda beton teknolojisindeki gelişmeler sayesinde, Ultra Yüksek Dayanımlı Betonlar (UYDB) daha kolay üretilebilir hale gelmiştir. Genellikle çok ince ve yüksek dayanımlı agrega ve çok düşük su/bağlayıcı oranı ile üretilen bu tür betonlar için standart üretim teknikleri ile $100 \mathrm{MPa}$ ve üzeri basınç dayanımları elde edilebilmektedir [5-7]. Özel karıştırıcılar, yüksek performanslı beton kimyasalları veya özel kür koşulları (1s1, basınç vb.) uygulanması durumunda ise çok daha yüksek dayanımlara (200 MPa ve üzeri) ulaşılabilmektedir [8-11].

Beton teknolojisindeki bu gelişmelere paralel olarak betonarme yapılarda bu betonların kullanımına yönelik çalışmalar da önem kazanmıştır. UYDB, birçok yapı elemanında geleneksel betonlara göre çeşitli avantajlar sağlama potansiyeline sahiptir. $\mathrm{Bu}$ bağlamda en önemli elemanlardan biri kirişlerdir. UYDB, basınç altındaki yüksek șekildeğiştirme kapasitesi nedeniyle kirişlerde yüksek donatı oranlarının kullanılmasına imkan vermektedir. Bu da elemanlardaki taşıma kapasitesini arttırarak önemli ekonomi sağlamaktadır. Buna karşın mevcut tasarım yönetmeliklerinde sünek davranış için öngörülen maksimum çekme donatısı oranları, bu tür özel betonların basınç altındaki kapasitesinin etkin olarak kullanılmasını sınırlamaktadır. UYDB'nin yüksek basınç kapasitesinden yararlanmak için yüksek dayanımlı çeliklerin kullanılması ya da geleneksel yumuşak çeliklerin yüksek oranda kullanılması gerekmektedir. Yapılan çalışmalarda, geleneksel donatılı ve UYDB içeren betonarme kirişlerin eğilme davranışlarında oldukça iyi performanslar elde edildiği ve yönetmeliklerde verilen donatı sınırlarının üzerine çıkılmasına rağmen belirli süneklik değerlerinin sağlandığı görülmektedir [12-17]. Ancak beton basınç dayanımı, kesit geometrisi, basınç donatısı oranı, sarg1 donatısı oranı vb. parametreler süneklik değerlerini etkilemekte ve geleneksel betonarme için yönetmeliklerde verilen tasarım esasları çok yüksek dayanımlı betonlar geçerli olmamaktadır [18]. Bu nedenle, kirişlerde UYDB'nin 
eğilme performansından etkin olarak yararlanabilmek için yeterli sünekliği sağlayacak çekme donatısı oranları üzerinde parametrik deneysel çalışmalara ihtiyaç duyulmaktadir.

$\mathrm{Bu}$ çalışmada, UYDB'nin betonarme kirişlerin eğilme davranışına etkilerinin incelenmesi amaçlanmıştır. Bunun için, standart karıştırıcılarla ve standart kür koşulları altında $120 \mathrm{MPa}$ ve üzeri basınç dayanımına sahip betonun üretilmesi öngörülmüştür. Çalışmada UYDB içeren düşük ve yüksek çekme donatısı oranlarına sahip dört adet betonarme kiriş hazırlanmış ve bu kirişlerin dört noktalı eğilme testleri gerçekleştirilmiştir. Çalışmada ayrıca UYDB ve normal dayanımlı beton (C25) kullanılarak kesit analizleri gerçekleştirilmiş ve sonuçlar yer değiştirme sünekliği, moment kapasitesi ve eğilme rijitliği parametreleri açısından karşılaştırılmıştır.

\section{Materyal ve yöntem}

\subsection{Ultra yüksek dayanımlı betonun özellikleri}

Çalışmada incelenen kirişlerde kullanılmak üzere 28 günlük basınç dayanımı en az 120 MPa olan UYDB üretilmesi öngörülmüştür. Betonun bağlayıcı kısmı CEM I 42.5 sınıf Portland çimentosu, silis dumanı ve yüksek fırın cürufundan oluşmaktadır. Agrega olarak iki farklı boyutta yüksek dayanımlı kuvars agregası kullanılmıştır. UYDB çok düşük su/bağlayıcı oranına sahip olduğundan, betonun işlenebilirliğinin sağlanması için ASTM C 494 [19] F tipi polikarboksilat eter esaslı yeni nesil süperakışkanlaştırıcı katkı kullanılmıştır. Betonu oluşturan bileşenler Şekil 1'de verilmiştir. Bu bileşenlerin $1 \mathrm{~m}^{3}$ beton için ağırlıkları Tablo 1'de [20], betonun bağlayıcı kısmını oluşturan bileşenlerin kimyasal ve fiziksel özellikleri Tablo 2'de verilmiştir.
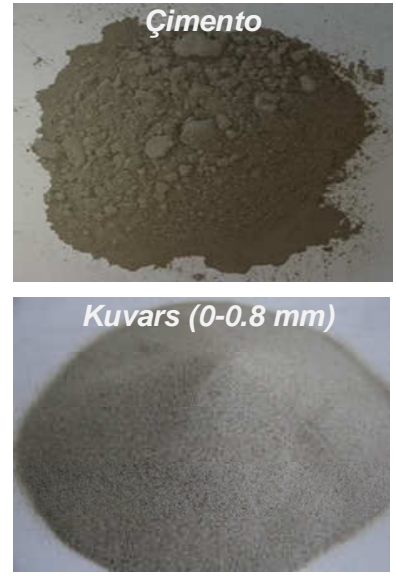
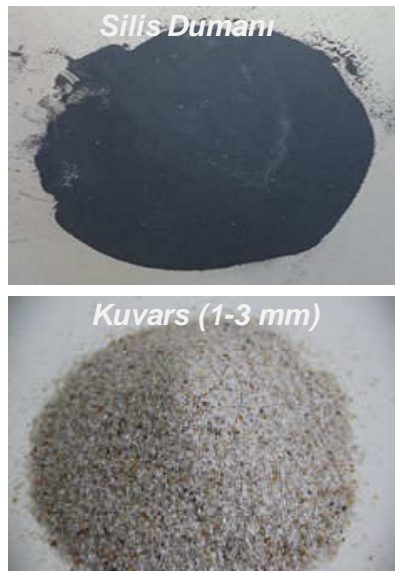
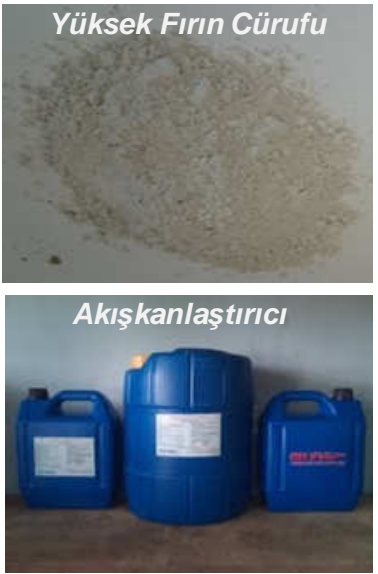

Şekil 1. UYDB' yi oluşturan bileşenler.

Tablo 1. Betonu oluşturan bileșenlerin miktarları $\left(\mathrm{kg} / \mathrm{m}^{3}\right)$.

\begin{tabular}{ccccccc}
\hline Çimento Silis Dumanı & $\begin{array}{c}\text { Yüksek Fırın } \\
\text { Cürufu }\end{array}$ & $\begin{array}{c}\text { Süper } \\
\text { Akışkanlaştırıcı }\end{array}$ & $\begin{array}{c}0-0.8 \mathrm{~mm} \\
\text { Kuvars }\end{array}$ & $\begin{array}{c}1-3 \mathrm{~mm} \\
\text { Kuvars }\end{array}$ & Su/ Bağlayıc1 \\
\hline 690 & 138 & 276 & 19 & 530 & 530 & 0.18 \\
\hline
\end{tabular}


Tablo 2. Betonun bağlayıcı kısmını oluşturan bileşenlerin kimyasal ve fiziksel özellikleri.

\begin{tabular}{lccc}
\hline \multicolumn{1}{c}{ Bileşen (\%) } & Çimento & Silis Dumanı & Yüksek Firın Cürufu \\
\hline $\mathrm{SiO}_{2}$ & 19.8 & $90-93$ & 41.49 \\
$\mathrm{Al}_{2} \mathrm{O}_{3}$ & 5.47 & $0.4-0.9$ & 16.34 \\
$\mathrm{Fe}_{2} \mathrm{O}_{3}$ & 3.46 & $1.0-2.0$ & 0.61 \\
$\mathrm{CaO}$ & 64.44 & $0.2-0.7$ & 29.26 \\
$\mathrm{MgO}$ & 1.30 & $0.9-1.3$ & 7.68 \\
$\mathrm{SO}_{3}$ & 2.67 & - & 1.90 \\
$\mathrm{Na}_{2} \mathrm{O}$ & 0.40 & $0.2-0.6$ & 0.80 \\
$\mathrm{~K}_{2} \mathrm{O}$ & 0.67 & $1.0-1.3$ & 1.10 \\
$\mathrm{Cl}$ & 0.012 & - & 0.01 \\
$\mathrm{Fe}_{2} \mathrm{O}_{3}$ & - & $1.0-2.0$ & - \\
Özgül yüzey $\left(\mathrm{m}^{2} / \mathrm{kg}\right)$ & 380 & 20000 & - \\
Yoğunluk $\left(\mathrm{g} / \mathrm{cm}^{3}\right)$ & 3.13 & 2.10 & - \\
\hline
\end{tabular}

\subsection{Test kirişlerinin özellikleri}

Çalışmada incelenmek üzere 4 adet $150 \times 250 \times 2500 \mathrm{~mm}$ boyutlarında test kirişi üretilmiștir. Kirișlerin geometrik özellikleri ve tipik donatı yerleșimleri Șekil 2'de verilmiştir. Kirişlerde basınç donatısı bulunmamaktadır. Kesme kırılmasını önlemek amacıyla salt eğilme bölgesi dışında $\phi 8 / 100$ etriye kullanılmıştır. Test kirişlerinin boyuna donatıları ve bunlara ait mekanik özellikler Tablo 3 'te verilmiştir. Çalışmada düşük çekme donatısı oranını $(\rho)$ temsil etmek amacıyla K1 kirişinde 0.009'luk boyuna donatı oranı kullanılmıştır. K2 kirişi yaklaşık olarak TS 500'de [21] verilen maksimum çekme donatısı oranına (0.019) sahiptir. K3 ve K4 kirişleri ise, TS 500'deki maksimum oranının üzerindeki yüksek donatı oranlarını temsil etmektedir. Bununla birlikte, incelen tüm kirişlerde çekme kırılması oluşması için boyuna donatı oranları dengeli donatı oranının $\left(\rho_{b}\right)$ altında tutulmuştur. Dengeli donatı oranı $\rho_{b}$ için geleneksel betonarmedeki esaslar kullanılmış ve tüm kirişlerde 0.066 olarak hesaplanmıştır. Test kirişlerindeki çekme donatılarının dengeli donatıya oranları Tablo 3'te verilmiştir.

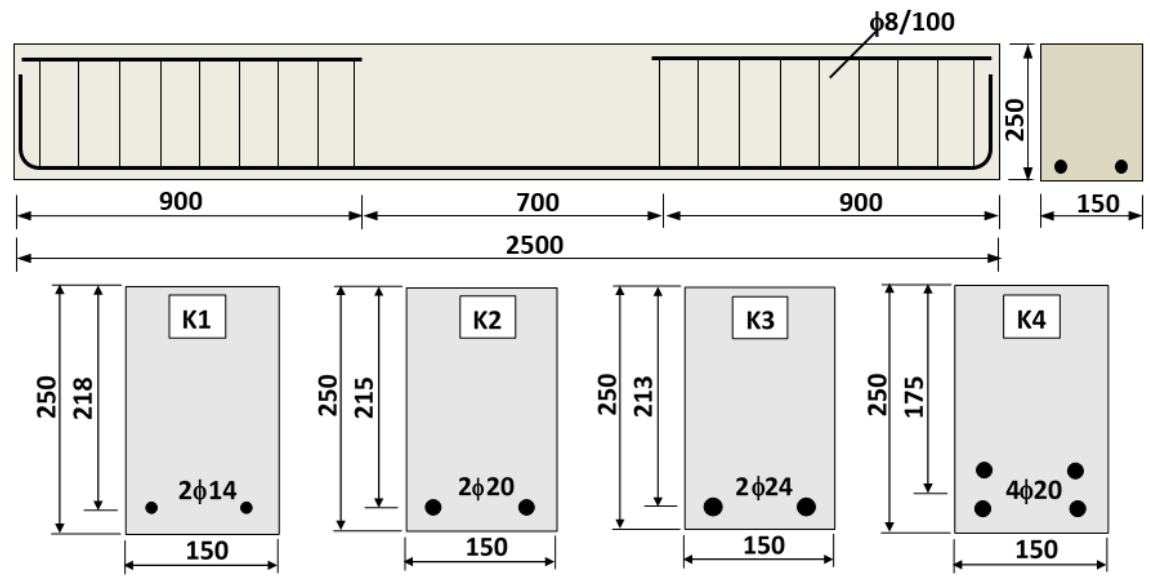

Şekil 2. Kirişlerin geometrik özellikleri ve tipik donatı yerleşimi.

Çalışmada kullanılan UYDB, $125 \mathrm{dm}^{3}$ kapasiteli standart bir panmikserde üretilmiş ve el arabası aracılığı ile çelik kalıplara yerleştirilmiştir (Şekil 3). UYDB'nin basınç dayanımını belirlemek amacıyla her bir kiriş için 6 adet 100x100x100 mm'lik küp 
numune alınmıştır. Kalıptan çıkarılan kiriş ve küp numuneleri test tarihine kadar laboratuvar ortamı sıcaklığında bekletilmiştir. Betonarme kirişlerde kullanılan betonun test günündeki basınç dayanımları Tablo 4'te verilmiştir.

Tablo 3. Kirişlerdeki boyuna donatılar ve mekanik özellikleri.

\begin{tabular}{|c|c|c|c|c|c|}
\hline \multirow{2}{*}{ Kiriş Kodu } & \multicolumn{2}{|c|}{ Çekme Donatısı } & \multirow{2}{*}{$\mathrm{f}_{\mathrm{y}}(\mathrm{MPa})$} & \multirow{2}{*}{$\mathrm{f}_{\mathrm{u}}(\mathrm{MPa})$} & \multirow{2}{*}{$\rho / \rho_{b}$} \\
\hline & Miktarı & Oran1 $(\rho)$ & & & \\
\hline K1 & $2 \phi 14$ & 0.009 & 469 & 590 & 0.136 \\
\hline $\mathrm{K} 2$ & $2 \phi 20$ & 0.019 & 462 & 654 & 0.288 \\
\hline $\mathrm{K} 3$ & $2 \phi 24$ & 0.028 & 491 & 606 & 0.424 \\
\hline $\mathrm{K} 4$ & $4 \phi 20$ & 0.043 & 468 & 661 & 0.652 \\
\hline
\end{tabular}
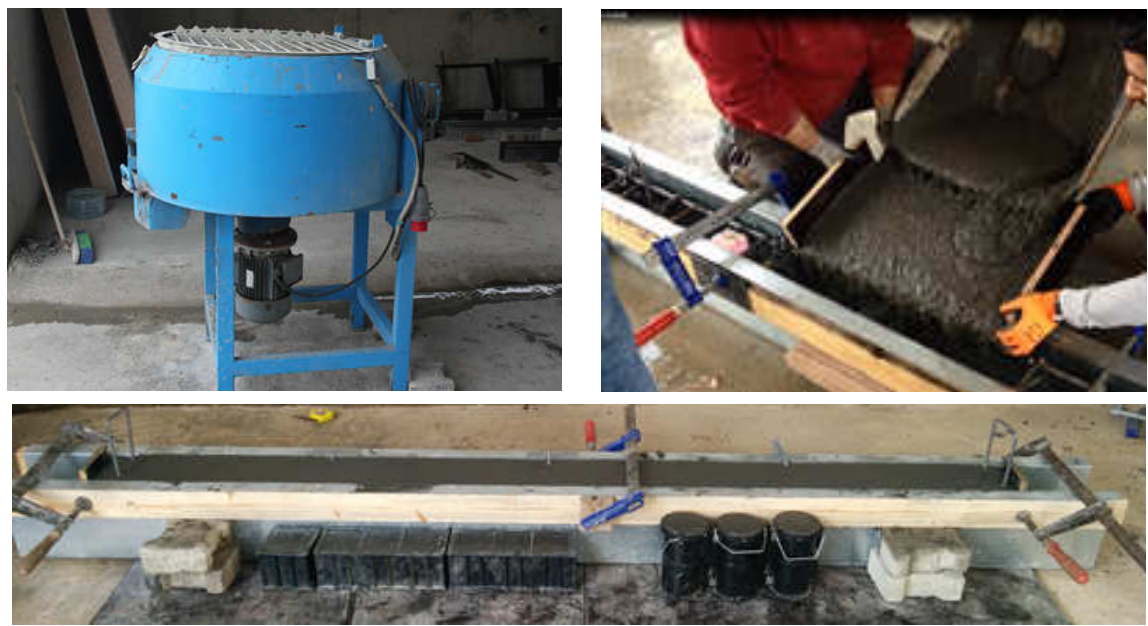

Şekil 3. UYDB'nin hazırlanması ve kalıplara yerleştirilmesi.

Tablo 4. Test kirişlerinin ortalama basınç dayanımları.

\begin{tabular}{ccccc}
\hline Kiriş Kodu & K1 & K2 & K3 & K4 \\
\hline Test Günü & 50 & 54 & 45 & 38 \\
Basınç Dayanımı $(\mathrm{MPa})$ & 135 & 133 & 132 & 139 \\
\hline
\end{tabular}

\subsection{Test düzenĕgi ve yapılan ölçümler}

Kirişlerin eğilme testleri, Balıkesir Üniversitesi Yapı Mekaniği Laboratuvarı'nda bulunan dört noktalı eğilme test düzeneği ile yapılmıştır. Bu düzenekteki $500 \mathrm{kN}$ kapasiteli hidrolik bir yük veren aracılığı ile kirişlerin testleri yer değiştirme kontrollü olarak yapılabilmektedir (Şekil 4).

Numunenin düşey yer değişstirmesini ölçmek için kiriş açıklık ortasına bir potansiyometrik cetvel ve uygulanan yükü ölçmek için yük verenin altına bir yük hücresi (load cell) yerleştirilmiştir. Yük, rijit çelik bir profil aracılığıyla aralarında 700 mm olan iki tekil yüke dönüştürülerek kirişe uygulanmıştır. Kiriş orta bölgesindeki eğriliği (birim dönmeyi) belirlemek amacıyla basınç ve çekme bölgesine iki adet potansiyometrik cetvel yerleştirilmiştir. Bu potansiyometrik cetveller en diş beton basınç lifindeki ve en alt beton çekme lifindeki yer değiştirmeleri 300 mm'lik bir bölgede rölatif olarak ölçmektedir. Böylece potansiyometrik cetvellerden elde edilen 
kısalma ve uzama değerlerinden yararlanılarak salt eğilme bölgesindeki ortalama eğrilik doğrudan belirlenmiştir (Șekil 5). Ayrıca, salt eğilme bölgesindeki betonun basınç altındaki şekil değiştirme kapasitesini belirlemek amacıyla beton yüzeyine şekil değiştirme ölçerler (strain gauges) yerleştirilmiştir.

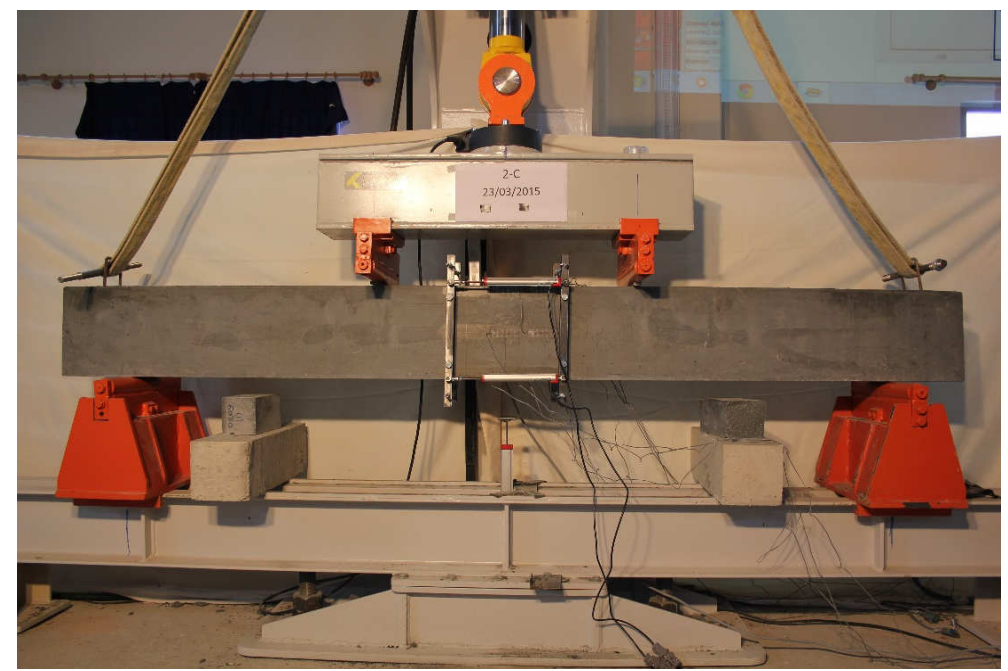

Şekil 4. Dört noktalı eğilme test düzeneği.

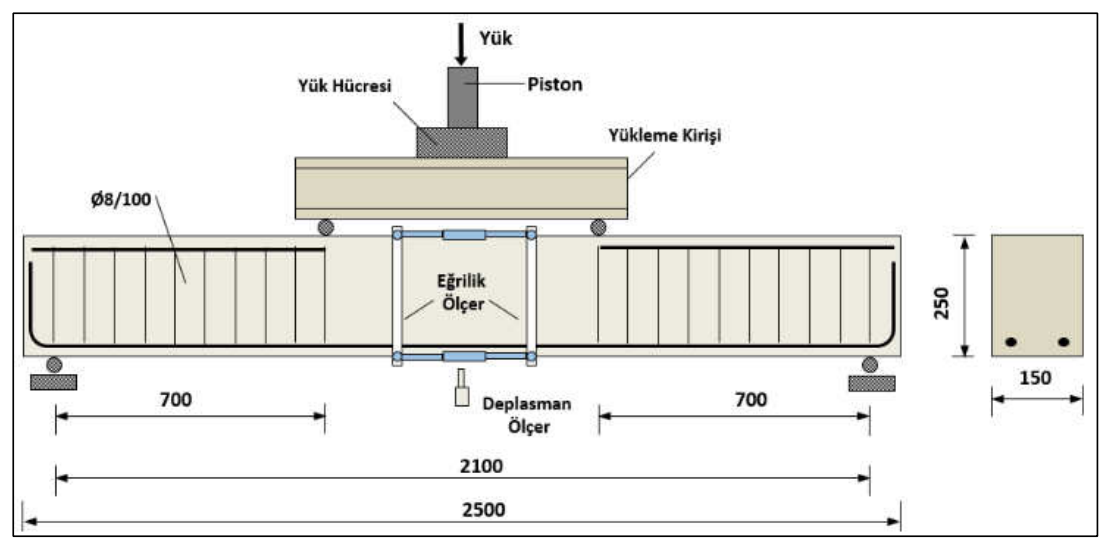

Şekil 5. Şematik yükleme ve ölçüm düzeneği.

\section{Deneysel çalışma sonuçları}

İncelenen kirişler göçme yüküne kadar yükleme yapılarak kırılma mekanizmaları belirlenmiştir. Çekme donatısı oranları dengeli donatı oranının altında olduğu için, beklenildiği gibi, tüm kirişlerde betonda ezilme olmadan önce donatı akmış ve testler basınç bölgesindeki betonun ezilmesiyle sonuçlanmıştır (Şekil 6). Tüm kirişlerde kesme (asal çekme) çatlakları gözlenmiş, ancak kirişlerin kesme kapasiteleri yeterli olduğu için kesme kırılması oluşmadan eğilme kapasitelerine ulaşılmıştır.

Test kirişlerinin eğilme davranışını değerlendirmek amacıyla, her bir kiriş için yükaçıklık ortası düşey yer değiştirme ve açıklık ortasındaki kiriş kesiti için moment-eğrilik grafikleri elde edilmiştir (Şekil 7, 8). K1 ve K3 kirişlerine ait testlerde, eğrilik ölçüm 
düzeneğinin sabitleme bölgesinde oluşan çatlaklar nedeniyle belirli bir yer değiştirmeden sonra veri alınamamıştır (Şekil 8).

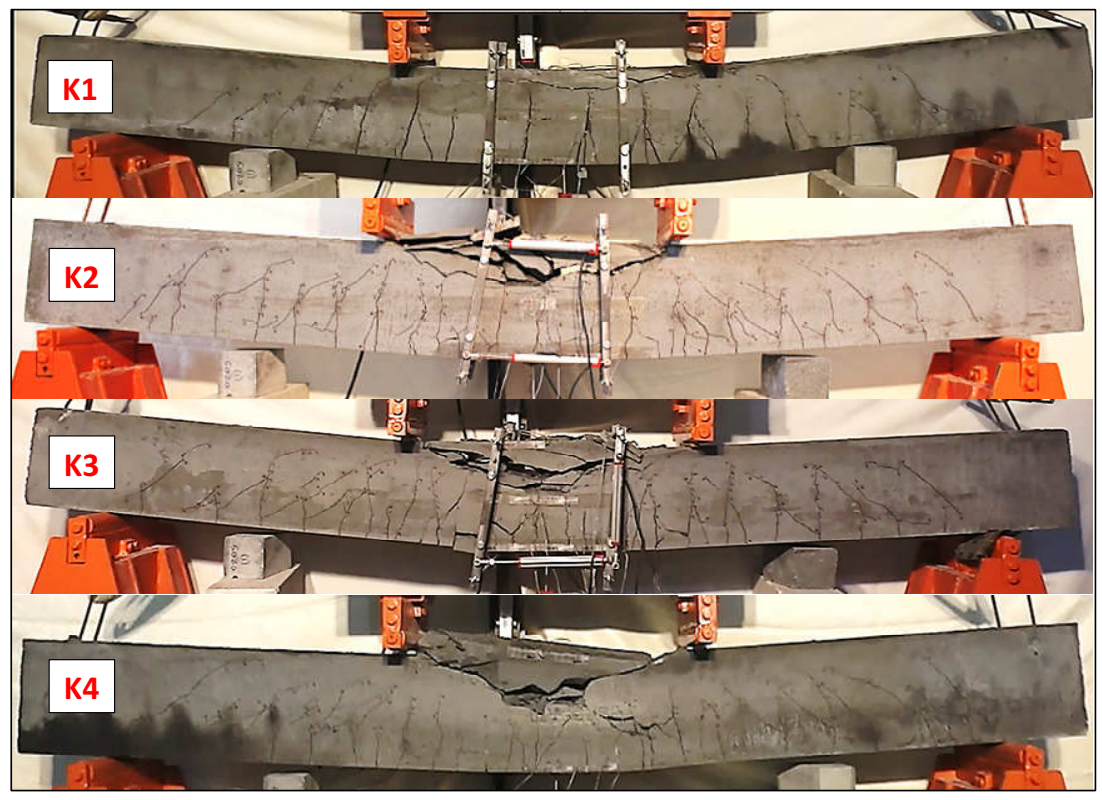

Şekil 6. Eğilme testi sonucu kırılma yüküne ulaşan betonarme kirişler.

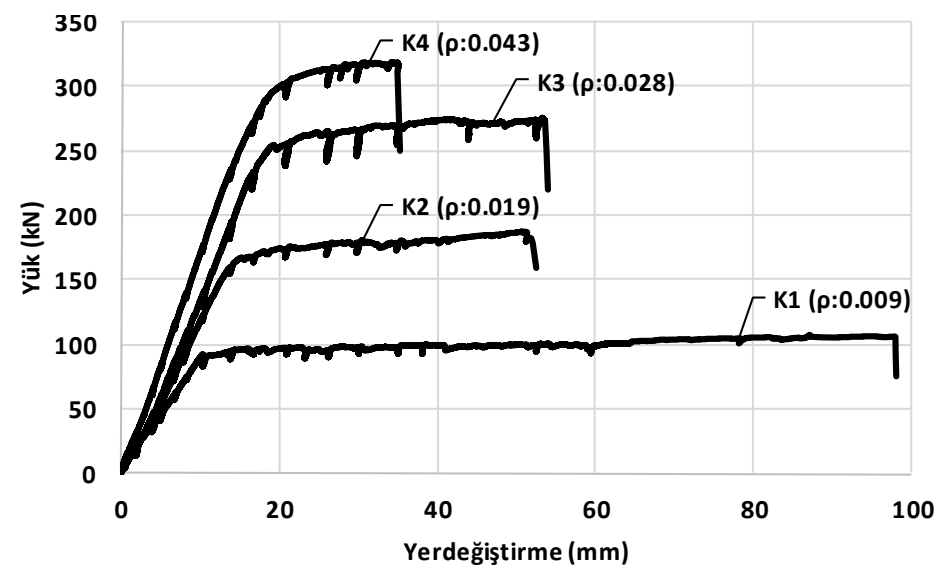

Şekil 7. Test kirişlerine ait yük-düşey yer değiştirme davranışlarının karşılaştırılması.

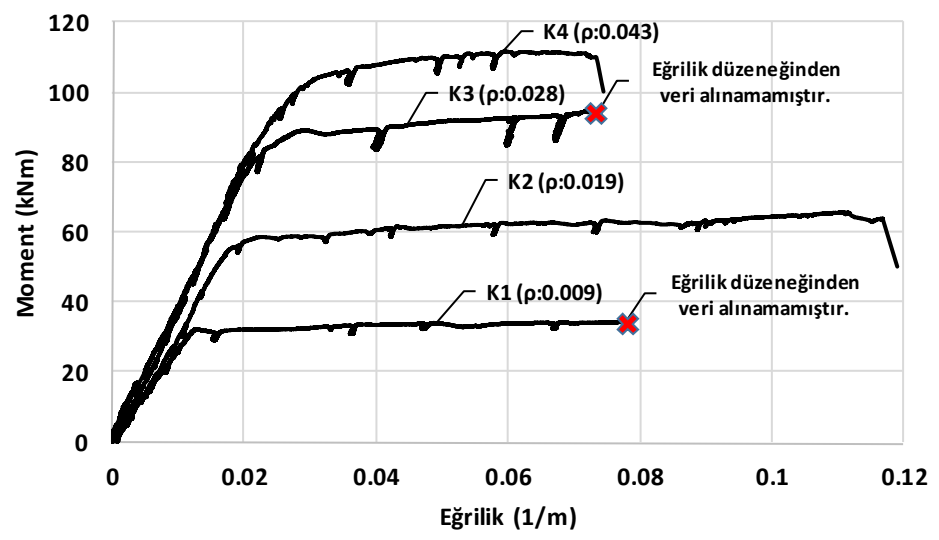

Şekil 8. Test kirişlerine ait moment-eğrilik davranışlarının karşılaştırılması. 
Yük-düşey yer değiştirme ilişkisinden yararlanarak akma yükü $\left(P_{y}\right)$, maksimum yük $\left(P_{u}\right)$, akma yer değiştirmesi $\left(\Delta_{y}\right)$ ve maksimum yer değiştirme $\left(\Delta_{u}\right)$ değerleri elde edilmiştir. Akma yer değiştirmesinin belirlenmesinde, elasto-plastik davranıştaki akmayı esas alan azaltılmış rijitlik yaklaşımı kullanılmıştır (Şekil 9) [22].

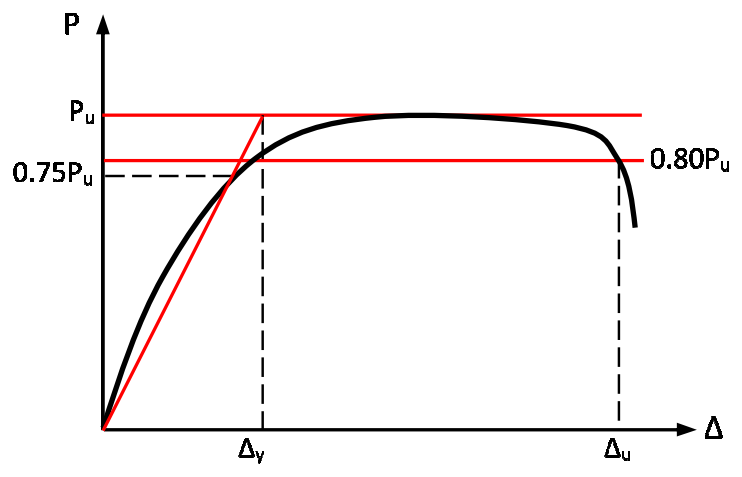

Şekil 9. Akma yer değiştirmesinin belirlenmesi [22].

Maksimum yer değiştirme ve akma yer değiştirmesi kullanılarak her bir kiriş için yer değiştirme sünekliğini ifade eden $\left(\Delta_{u} / \Delta_{y}\right)$ değerleri hesaplanmıştır (Tablo 5). Benzer şekilde moment-eğrilik ilişkilerinden yararlanılarak akma eğriliği $\left(\phi_{y}\right)$, maksimum eğrilik $\left(\phi_{u}\right)$ ve eğrilik sünekliğini ifade eden $\left(\phi_{u} / \phi_{y}\right)$ değerleri hesaplanmış ve Tablo 5 'te verilmiştir.

Tablo 5. Kirişlerin eğilme testlerinden elde edilen karakteristik değerler.

\begin{tabular}{ccccccccc}
\hline Kiriş Kodu & $\mathrm{P}_{\mathrm{y}}(\mathrm{kN})$ & $\Delta_{\mathrm{y}}(\mathrm{mm})$ & $\phi_{\mathrm{y}}(1 / \mathrm{m})$ & $\mathrm{P}_{\mathrm{u}}(\mathrm{kN})$ & $\Delta_{\mathrm{u}}(\mathrm{mm})$ & $\phi_{\mathrm{u}}(1 / \mathrm{m})$ & $\Delta_{\mathrm{u}} / \Delta_{\mathrm{y}}$ & $\phi_{\mathrm{u}} / \phi_{\mathrm{y}}$ \\
\hline $\mathrm{K} 1$ & 91.46 & 12.05 & - & 107.13 & 97.87 & - & 8.12 & - \\
$\mathrm{K} 2$ & 167.31 & 16.00 & 0.021 & 187.19 & 52.12 & 0.117 & 3.26 & 5.57 \\
$\mathrm{~K} 3$ & 251.10 & 19.80 & - & 275.32 & 53.65 & - & 2.71 & - \\
$\mathrm{K} 4$ & 295.06 & 19.10 & 0.029 & 318.88 & 35.00 & 0.073 & 1.83 & 2.52 \\
\hline
\end{tabular}

İncelenen tüm kirişler için donatı artışına bağlı olarak, beklenildiği gibi, dayanımların ve çatlamış kesit rijitliklerinin $\left(E I_{c}\right)$ artış gösterdiği, buna karşın sünekliklerin azaldığ görülmüşstür (Şekil 7,8 ve Tablo 5). Maksimum donatı oranı koşulunun aşıldığ $\mathrm{K} 3$ ve K4 kirişlerinde önemli yük ve moment taşıma kapasitesi artışları elde edilirken, sünek davranışın da sağlandığ gözlemlenmiştir (Tablo 5).

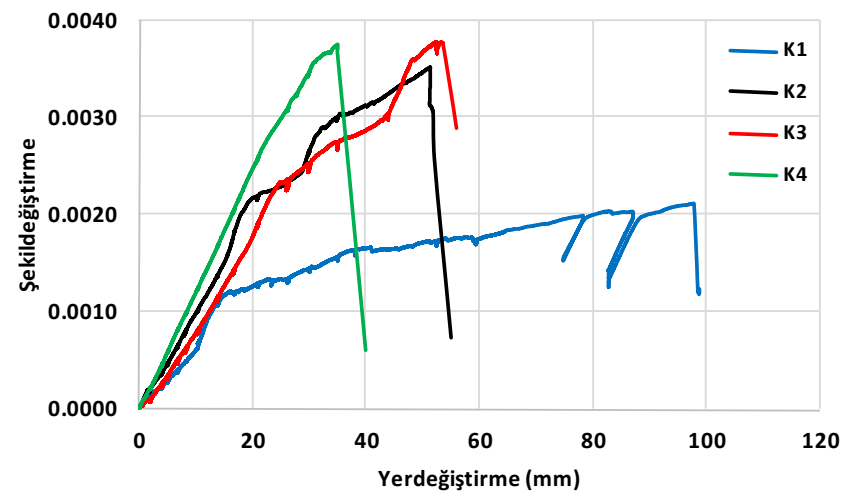

Şekil 10. Betondaki maksimum şekil değiştirmelerin donatı oranına göre değişimi. 
Kiriş orta bölgesinde beton yüzeyine yerleştirilen șekil değiştirme ölçerlerden alınan verilerin kiriş düşey yer değiştirmesi ile değişimi Şekil 10'da verilmiştir. En diş beton basınç lifindeki maksimum şekil değiştirmenin genel olarak 0.0035 ile 0.0037 arasında değiştiği belirlenmiştir.

\subsection{Deneysel ve teorik sonuçların karşılaştırılması}

Çalışmada incelenen kirişlerin açıklık ortası kesitinde deneysel olarak elde edilen moment-eğrilik ilişkileri teorik kesit analizi sonuçları ile karşılaştırılmıştır. Kesit analizlerinde, UYDB'nin basınç altındaki davranışı için Betonkalender' de [23] önerilen beton modeli, çekme altındaki davranışı için ise Fib 2010'da [24] önerilen model kullanılmıştır (Şekil 11).

a)

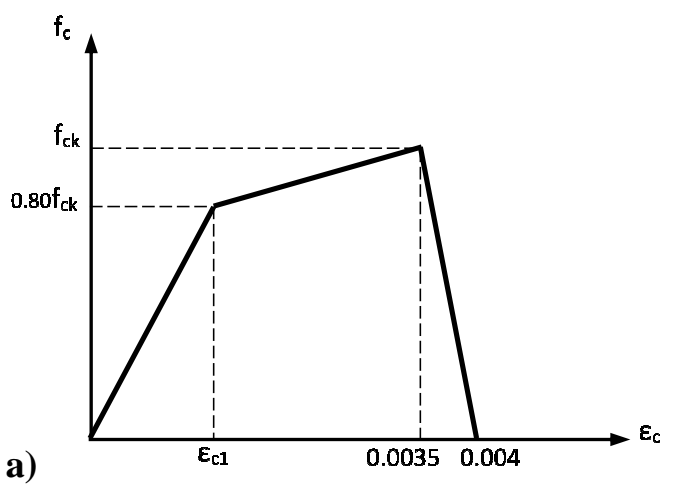

b)

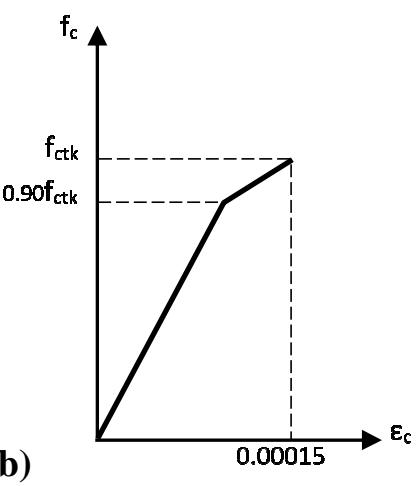

Şekil 11. a) UYDB için basınç davranış modeli [23], b) UYDB için çekme davranış1 modeli [24].

UYDB'ye ait basınç modelinde elastisite modülü $\left(E_{c}\right)$, (1) bağıntısı ile hesaplanmış ve modeldeki $\varepsilon_{c 1}$ değeri basınç dayanımlarına bağlı olarak elde edilmiştir (Şekil 11).

$$
E_{c}=8800\left(f_{c k}+8\right)^{1 / 3}
$$

$\mathrm{Bu}$ bağıntıda $f_{c k}$ betonun karakteristik basınç dayanımını ifade etmektedir. Betonun çekme dayanımı $\left(f_{c t k}\right),(2)$ bağıntısı ile belirlenmiş ve çekmede maksimum uzama şekil değiştirmesi 0.00015 alınmıştır [24].

$$
f_{c t k}=2.12 \ln \left[1+0.1\left(f_{c k}+8\right)\right]
$$

Çelik için ise DBYBHY-2007'de [25] önerilen model esas alınmış ve buna ait karakteristik değerler çekme testlerinden elde edilmiştir. Betonarme kesitler için moment-eğrilik analizleri SAP2000 Section Designer modülü ile gerçekleştirilmiştir [26]. Göz önüne alınan farklı kiriş kesitlerine ait deneysel ve teorik moment-eğrilik grafikleri Şekil 12'de verilmiştir. Kirişlerin kırılma (göçme) durumuna karşı gelen deneysel ve teorik eğilme momentleri Tablo 6' da verilmiştir.

Deneysel ve teorik sonuçların, eğilme rijitlikleri ve kırılma (göçme) momentleri bakımından genel olarak uyumlu olduğu görülmektedir (Şekil 12, Tablo 6). Eğrilik ölçümleri tamamlanan K2 ve K4 kirişlerinde maksimum eğrilik değerlerinin de uyumlu olduğu söylenebilmektedir (Şekil 12). Buna göre, yapılan kesit analizlerinin 
plastikleşmenin meydana geldiği orta bölgedeki (300 mm'lik) eğilme davranışını belirli yaklaşıklıkla temsil edebildiği görülmüştür.

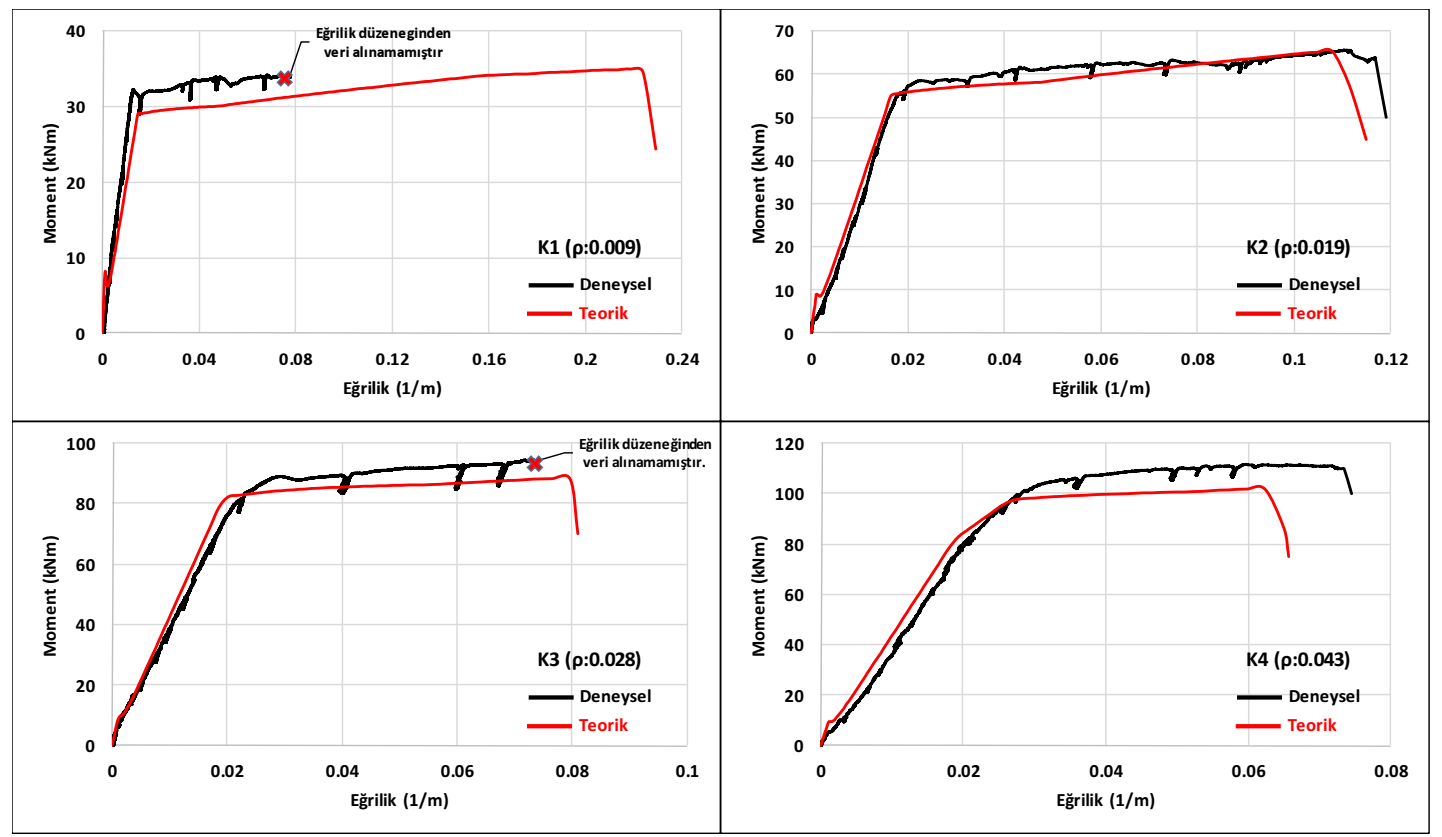

Şekil 12. Test kirişinin deneysel ve teorik moment-eğrilik davranışları.

Tablo 6. Teorik ve deneysel kırılma momentleri.

\begin{tabular}{cccc}
\hline Kiriş Kodu & $\mathrm{M}_{\mathrm{u} \text { (Teorik) }}(\mathrm{kNm})$ & $\mathrm{M}_{\mathrm{u} \text { (Deneysel) }}(\mathrm{kNm})$ & $\mathrm{M}_{\mathrm{u} \text { (Deneysel) }} / \mathrm{M}_{\mathrm{u} \text { (Teorik) }}$ \\
\hline $\mathrm{K} 1$ & 34.58 & 37.03 & 1.07 \\
$\mathrm{~K} 2$ & 65.19 & 63.69 & 0.98 \\
$\mathrm{~K} 3$ & 88.04 & 96.60 & 1.10 \\
$\mathrm{~K} 4$ & 101.80 & 109.84 & 1.08 \\
\hline
\end{tabular}

Deneysel ve teorik kırılma (göçme) momentlerinin belirli bir yaklaşıklıkla elde edilmesi, UYDB için 0.0035'lik maksimum şekil değiştirme değerinin beton ezilmesini temsil ettiğini göstermiştir. Bu sonuç, deneysel olarak elde edilen maksimum şekil değiştirme değerleri ile de uyumludur (Şekil 10).

\subsection{UYDB ve normal dayanımlı beton içeren kiriş davranışlarının karşılaştırılması}

$\mathrm{Bu}$ bölümde, betonarme kirişlerde UYDB kullanımının moment taşıma kapasitesi, süneklik ve eğilme rijitliği bakımından normal dayanımlı betona göre avantajlarının ortaya konulması amaçlanmıştır. Bunun için, çalışmada incelenen kiriş kesitlerinin sadece beton basınç dayanımları değiştirilerek C25 sınıfı beton için moment-eğrilik analizleri yapılmıştır. Elde edilen sonuçlar, UYDB'ye ait teorik sonuçlarla karşılaştırılmıştır. C25 sınıfı beton için DBYBHY-2007'de önerilen sargısız beton modeli esas alınmıştır. UYDB ve C25 sınıfi beton için maksimum beton şekil değiştirme değeri $\left(\varepsilon_{c u}\right) 0.0035$ alınmıştır. Her bir kiriş kesiti için elde edilen momenteğrilik ilişkileri Şekil 13'te karşılaştırmalı olarak verilmiştir.

Moment-eğrilik ilişkilerinden yararlanarak, Şekil 14'te gösterildiği gibi kesitlerin çatlamış kesit rijitlikleri $\left(E I_{c}\right)$, moment taşıma kapasiteleri $\left(M_{u}\right)$, akma eğrilikleri $\left(\phi_{y}\right)$, maksimum eğrilikleri $\left(\phi_{u}\right)$ ve eğrilik süneklikleri $\left(\phi_{u} / \phi_{y}\right)$ belirlenmiştir (Tablo 7). 


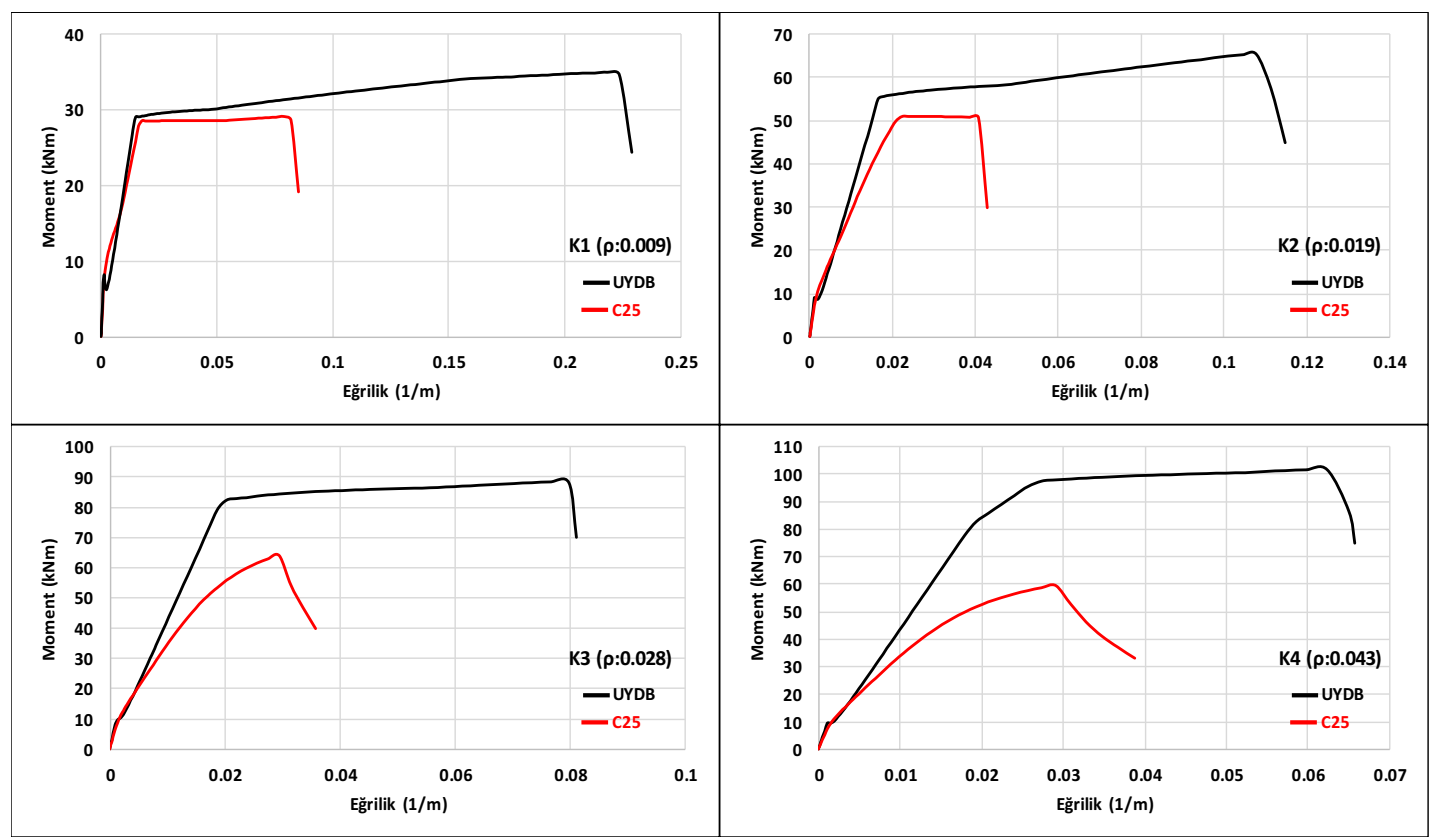

Şekil 13. UYDB ve C25 için moment-eğrilik ilişkilerinin karşılaştırılması.

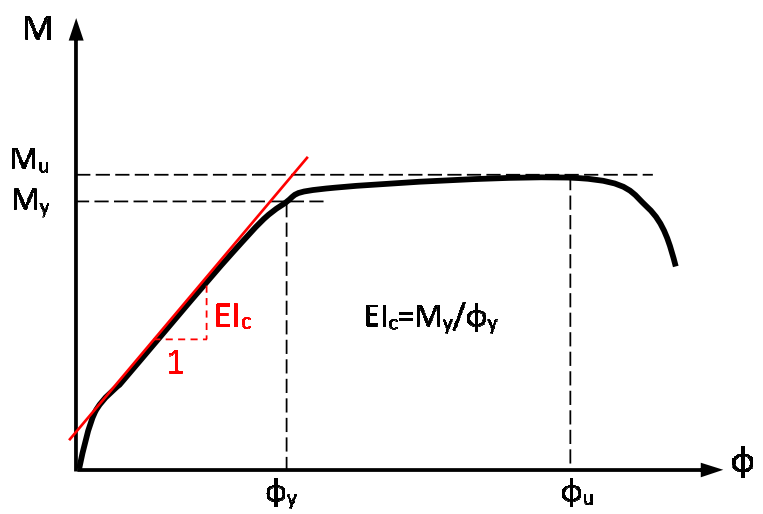

Şekil 14. Moment-Eğrilik ilişkisine ait karakteristik değerler.

İncelenen kiriş kesitleri için UYDB kullanılarak elde edilen süneklik, moment taşıma kapasitesi ve çatlamış kesit eğilme rijitlikleri, C25 betonu kullanılarak elde edilen değerlere oranlanmış ve Şekil 15'te karşılaștırılmıştır.

Tablo 7. UYDB ve C25 betonu için kirişlerin eğilme davranışına ait karakteristik parametreler.

\begin{tabular}{ccccccc}
\hline Kiriş Kodu & Beton & $\phi_{\mathrm{v}}(1 / \mathrm{m})$ & $\phi_{\mathrm{u}}(1 / \mathrm{m})$ & $\phi_{\mathrm{u}} / \phi_{\mathrm{y}}$ & $\mathrm{M}_{\mathrm{u}}(\mathrm{kNm})$ & $\mathrm{EI}_{\mathrm{c}}\left(\mathrm{kNm}^{2}\right)$ \\
\hline \multirow{2}{*}{$\mathrm{K} 1$} & UYDB & 0.015 & 0.224 & 14.93 & 34.93 & 1973 \\
& C25 & 0.016 & 0.082 & 5.13 & 29.17 & 1475 \\
$\mathrm{~K} 2$ & UYDB & 0.017 & 0.108 & 6.35 & 65.19 & 3303 \\
& C25 & 0.021 & 0.041 & 1.95 & 50.97 & 2194 \\
\multirow{2}{*}{ K3 } & UYDB & 0.019 & 0.090 & 4.74 & 88.26 & 4201 \\
& C25 & - & - & - & 64.06 & 2842 \\
\multirow{2}{*}{ K4 } & UYDB & 0.018 & 0.068 & 3.78 & 101.8 & 4342 \\
& C25 & - & - & - & 59.68 & 2919 \\
\hline
\end{tabular}


UYDB ve C25 betonu için kesit davranışları karşılaştırıldığında; UYDB'nin eğrilik sünekliğini 2.91-4.74 kat, çatlamış kesit eğilme rijitliğini 1.34-1.51 kat ve moment taşıma kapasitesini 1.20-1.71 kat arttırdığı belirlenmiştir (Şekil 15). C25 betonu kullanılması durumunda, TS 500'te verilen maksimum donatı oranının aşıldığ $\mathrm{K} 3$ ve K4 kirişlerinde sünek davranış elde edilemediği görülmektedir (Şekil 13).

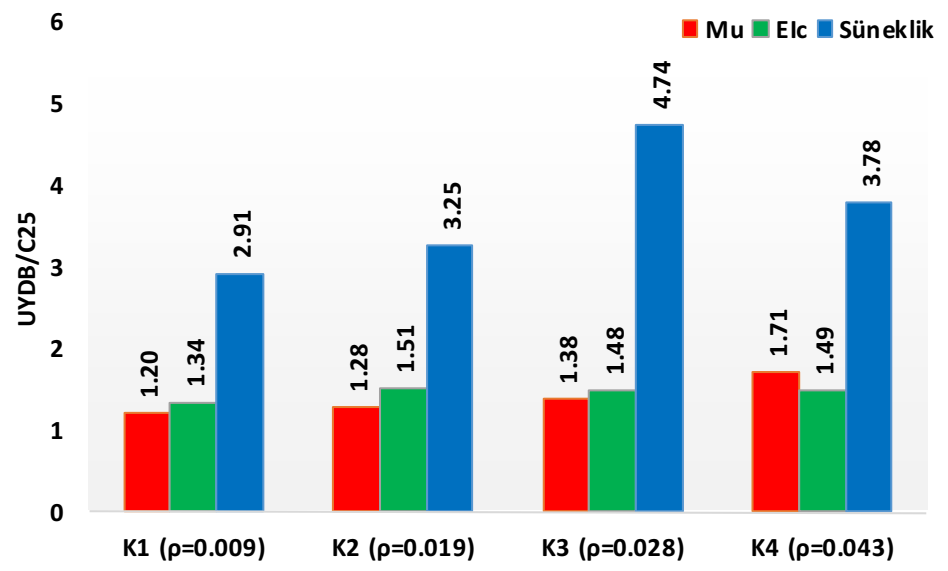

Şekil 15. Eğilme davranışına ait parametrelerinin oransal karşılaştırılması (UYDB/C25).

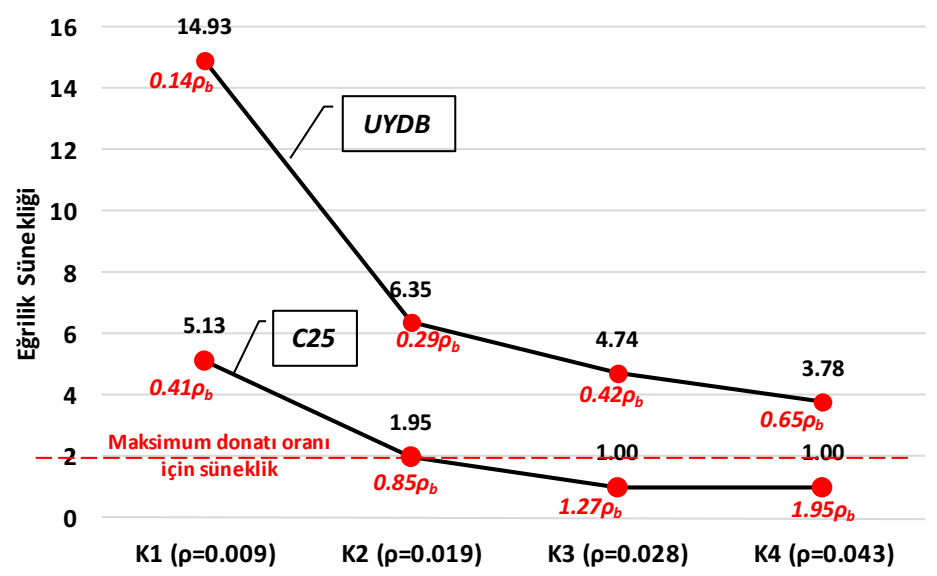

Şekil 16. UYDB ve C25 betonu için kiriş kesitlerinin eğrilik sünekliğinin değişimi.

Şekil 16' da UYDB ve C25 betonu için kiriş kesitlerinde elde edilen eğrilik sünekliğinin donatı oranıyla değişimi gösterilmiştir. K2 kirişinin donatı içeriği, TS 500'e göre maksimum donatıya karşı gelmektedir. Bu kirişte C25 betonu kullanılması durumunda ise eğrilik sünekliği 1.95 olarak elde edilmiştir. Buna göre, incelenen kiriş kesiti için TS 500'de öngörülen en düşük süneklik değerinin 1.95 olduğu söylenebilmektedir. UYDB kullanılması durumunda, \%2'lik maksimum donatı oranının aşıldığı kiriş kesitlerinde dahi minimum sünekliğin çok üzerinde süneklikler elde edildiği görülmektedir (Şekil 16). Analizler sonucunda UYDB ile üretilen yüksek donatı oranına sahip kirişlerin yeterli sünekliği sağladığı, hatta daha yüksek donatı oranlarının da kullanılabileceği söylenebilmektedir. 


\section{Sonuçlar}

Çalışmada, UYDB'nin betonarme kirişlerin eğilme davranışına etkilerinin incelenmesi amaçlanmıştır. Deneysel kısımda ortalama $135 \mathrm{MPa}$ ortalama basınç dayanımına sahip UYDB kullanılarak düşük ve yüksek donatı oranlarına sahip dört adet betonarme kiriş üretilmiş ve dört noktalı eğilme altında test edilmiştir. Daha sonra, test kirişleri için UYDB ve normal dayanımlı beton kullanılarak kesit analizleri gerçekleştirilmiş ve sonuçlar karşılaştırılmıştır.

- Çalışmada kullanılan UYDB, standart karıştırıcılar ve standart kür koşulları altında üretilmekte ve kendiliğinden yerleşen özelliktedir. $\mathrm{Bu}$ özellikleri nedeniyle betonun pratikte uygulanabilir olduğu düşünülmektedir.

- Kirişler üzerinde yapılan teorik analizler deneysel sonuçlarla karşılaştırıldığında; literatürde UYDB için önerilen teorik modellerin deneysel sonuçlarla oldukça uyumlu olduğu görülmüştür.

- Kirişlerdeki çekme donatısı oranları arttıkça UYDB'nin eğilme performansı normal dayanımlı betonla kıyaslandığında önemli artış göstermiştir. UYDB'nin eğilme sünekliğinde 4.74 kat, moment taşıma kapasitesinde \%71, çatlamış kesit eğilme rijitliğinde \% 51'e varan önemli artışlar sağlayabildiği belirlenmiştir. Bu artışlar, TS 500'de verilen maksimum donatı sınırının aşılması durumu için de geçerlidir. Düşük donatı oranları için, beton basınç bölgesindeki yüksek şekil değiştirme kapasiteden yararlanılamaması nedeniyle UYDB'nin performansının etkin olarak kullanılamadığı söylenebilir.

UYDB ile üretilen kirişlerde TS 500' de verilen maksimum donatı sınırının aşılmasına rağmen kirişlerin yeterli sünekliği sağladığı, hatta daha yüksek donatı oranlarının da kullanılabileceği düşünülmektedir.

Çalışmada incelenen kirişlerde süneklik açısından en elverişsiz durumların incelenmesi amaçlandığından sadece çekme donatısı kullanılmıştır. Basınç donatısı ve yeterli sarg1 donatısı kullanıldığında elde edilen sünekliklerin büyük artış göstereceği söylenebilir.

Bu çalışmada elde edilen sonuçlar, kirişlerde UYDB'nin kullanımının eğilme davranışı bakımından önemli avantajlar sağlayabileceğini göstermektedir. Bununla birlikte, bu betonlara ait tasarım esaslarının oluşturulabilmesi için çok daha fazla sayıda parametrik deneysel çalışmalara ihtiyaç bulunduğu düşünülmektedir.

\section{Teşekkür}

Yazarlar, bu çalışmada kullanılan Ultra Yüksek Dayanımlı Betonun geliştirilmesine 113M432 nolu proje kapsamında destek sağlayan TÜBİTAK'a, akışkanlaştırıcıların teminindeki katkılarından dolayı BASF firmasına ve yüksek fırın cürufunun teminindeki katkılarından dolayı BURSA ÇİMENTO firmasına teşekkürlerini sunarlar. 


\section{Kaynaklar}

[1] Voo, Y.L., Poon, W.K. ve Foster, S.J., Shear strength of steel fiber-reinforced ultrahigh-performance concrete beams without stirrups, Journal of Structural Engineering, 136, 1393-1400, (2010).

[2] Türker, K., Birol, T., Yavaş, A. ve Hasgül, U., Ultra Yüksek Performanslı Lifli Beton İçeren Kirişlerde Etkin Çelik Lif Tipi İncelemesi, Afyon Kocatepe Üniversitesi Fen ve Mühendislik Bilimleri Dergisi, 16, 776-785, (2016).

[3] Aitchin, P.C., The durability characteristics of high performance concrete: a review, Cement and Concrete Composites, 25, 4-5, 409-420, (2003).

[4] Voo, Y.L. ve Foster, S.J., Characteristics of ultra-high performance 'ductile' concrete and its impact on sustainable construction, The IES Journal Part A: Civil \& Structural Engineering, 3, 3, 168-187.

[5] Yudenfreund, M., Skalny, J., Mikhail, R.S. ve Brunauer, S., Hardened portland cement pastes of low porosity, II. Exploratory studies. Dimensional changes, Cement and Concrete Research, 2, 3, 331-348, (1972).

[6] Roy, D.M., Gouda, G.R. ve Bobrowsky, A., Very high strength cement pastes prepared by hot pressing and other high pressure techniques, Cement and Concrete Research, 2, 349-366, (1972).

[7] Bache, H. H., Densified cement/ultrafine particle-based materials, In: 2nd int. conference on superplasticizers in concrete, Ottawa, 10-12 June, (1981).

[8] Wille, K., Naaman, A.E., El-Tawil, S. ve Parra-Montesinos, G.J., Ultra-high performance concrete and fiber reinforced concrete: achieving strength and ductility without heat curing, Materials and Structures, 45, 3, 309-324, (2012).

[9] El-Dieb, A.S., Mechanical, durability and microstructural characteristics of ultra-high-strength self-compacting concrete incorporating steel fiber, Materials and Design, 30, 4286-92, (2009).

[10] Kamal, M.M., Safan, M.A., Etman, Z.A. ve Salama, R.A., Production of ultra high-strength concrete using local materials, Engineering Research Journal, 36, 1, 91-100, (2013).

[11] Wang, C., Yang, C., Liu, F., Wan, C. ve Pu, X., Preparation of ultra-high performance concrete with common technology and materials, Cement and Concrete Composites, 34, 538-544, (2012).

[12] Rashid, M.A. ve Mansur, M.A., Reinforced high-strength concrete beams in flexure, ACI Structural Journal, 102, 3, 462-471, (2005).

[13] Jang, I.Y., Park, H.G., Kim, S.S., Kim, J.H. ve Kim, Y.G., On the ductility of high-strength concrete beams, International Journal of Concrete Structures and Materials, 2, 2, 115-122, (2008).

[14] Shin, S.W., Kang, H., Ahn, J. M. ve Kim, D.W., Flexural capacity of singly reinforced beam with $150 \mathrm{MPa}$ ultra high-strength concrete, Indian Journal of Engineering and Material Science, 17, 414-426, (2010).

[15] Bai, Z.Z. ve Au, F.T.K., Flexural ductility design of high-strength concrete beams, The Structural Design of Tall and Special Buildings, (2011).

[16] Mansur, M.A., Chin, M.S. ve Wee, T.H., Flexural behavior of high-strength concrete beams, ACI Structural Journal, 94, 6, 663-673, (1997).

[17] Shin, S.W., Ghosh, S.K. ve Moreno, J., Flexural ductility of ultra-high strength concrete members, ACI Structural Journal, 86, 4, 394-400, (1989). 
[18] Wu, Z., Choi, W., Mirmiran, A., Rizkalla, S. ve P. Zia, P., Flexural behavior and design of high-strength concrete members, ACI Structural Journal, 228, 421438, (2005).

[19] ASTM C494 / C494M-15a, Standard specification for chemical admixtures for concrete, ASTM International, West Conshohocken, PA, (2015).

[20] Birol, T., Ultra yüksek performanslı lifli beton ile üretilen betonarme kirişlerin eğilme davranışının incelenmesi, Doktora Tezi, Balıkesir Üniversitesi, Fen Bilimleri Enstitüsü, Balıkesir, (2016).

[21] TS 500, Betonarme yapıların tasarım ve yapım kuralları, Türk Standartları Enstitüsü, Ankara, (2000).

[22] Park, R., Ductility evaluation from laboratory and analytical testing, Proceedings of the 9th World Conference on Earthquake Engineering, Tokyo, Kyoto, 8, 605-616, (1988).

[23] Fehling, E., Schmidt, M., Walraven, J., Leutbecher, T. ve Fröhlich, S., UltraHigh Performance Concrete UHPC, Betonkalander, Wilhelm Ernst \& Sohn, (2014).

[24] Fédération International du Bêton, International Federation for structural concrete(fib). fib Model code for concrete structures, Ernst \&Sohn, (2010).

[25] DBYBHY, Deprem bölgelerinde yapılacak binalar hakkında yönetmelik, TDY 2007, Bayındırlık ve İskan Bakanlığı, Ankara, (2007).

[26] CSI, Integrated finite element analysis and design of structures basic analysis reference manual, SAP2000V.8. Computers and Structures, Inc. C.A., USA, (2002). 